\title{
Global guidance on environmental life cycle impact assessment indicators: Progress and case study
}

Frischknecht, Rolf; Fantke, Peter; Tschümperlin, Laura ; Niero, Monia; Anton, Assumpcio; Bare, Jane; Boulay, Anne-Marie; Cherubini, Francesco ; Hauschild, Michael Zwicky; Henderson, Andrew

Total number of authors:

20

Published in:

International Journal of Life Cycle Assessment

Link to article, DOI:

10.1007/s11367-015-1025-1

Publication date:

2016

Document Version

Peer reviewed version

Link back to DTU Orbit

Citation (APA):

Frischknecht, R., Fantke, P., Tschümperlin, L., Niero, M., Anton, A., Bare, J., Boulay, A-M., Cherubini, F., Hauschild, M. Z., Henderson, A., Levasseur, A., McKone, T. E., Michelsen, O., i Canals, L. M., Pfister, S., Ridoutt, B., Rosenbaum, R. K., Verones, F., Vigon, B., \& Jolliet, O. (2016). Global guidance on environmental life cycle impact assessment indicators: Progress and case study. International Journal of Life Cycle Assessment, 21, 429-442. https://doi.org/10.1007/s11367-015-1025-1

\section{General rights}

Copyright and moral rights for the publications made accessible in the public portal are retained by the authors and/or other copyright owners and it is a condition of accessing publications that users recognise and abide by the legal requirements associated with these rights.

- Users may download and print one copy of any publication from the public portal for the purpose of private study or research.

- You may not further distribute the material or use it for any profit-making activity or commercial gain

- You may freely distribute the URL identifying the publication in the public portal 


\title{
Global guidance on environmental life cycle impact assessment indicators: Progress and case study
}

Rolf Frischknecht ${ }^{\mathrm{a}}$, Peter Fantke ${ }^{\mathrm{b}}$, Laura Tschümperlin ${ }^{\mathrm{a}}$, Monia Niero ${ }^{\mathrm{b}}$, Assumpció Antón ${ }^{\mathrm{c}}$, Jane Bare ${ }^{\mathrm{d}}$, AnneMarie Boulay ${ }^{\mathrm{e}}$, Francesco Cherubini ${ }^{\mathrm{f}}$, Michael Z. Hauschild ${ }^{\mathrm{b}}$, Andrew Henderson ${ }^{\mathrm{d}}$, Annie Levasseur ${ }^{\mathrm{e}}$, Thomas E. McKone $^{\mathrm{g}}$, Ottar Michelsen ${ }^{\mathrm{h}}$, Llorenç Milà i Canals ${ }^{\mathrm{i}}$, Stephan Pfister ${ }^{\mathrm{j}}$, Brad Ridoutt ${ }^{\mathrm{k}}$, Ralph K. Rosenbaum, Francesca Verones ${ }^{\mathrm{f}}$, Bruce Vigon $^{\mathrm{p}}$, Olivier Jolliet ${ }^{\mathrm{n}}$.

Corresponding author: Rolf Frischknecht, treeze Ltd.

atreeze Ltd., Uster, Switzerland.

${ }^{\mathrm{b}}$ Department of Management Engineering, Technical University of Denmark, Kgs. Lyngby, Denmark.

${ }^{c}$ IRTA, Institute for Food and Agricultural Research and Technology, Cabrils, Barcelona, Spain

${ }^{\mathrm{d}}$ United States Environmental Protection Agency, National Risk Management Research Laboratory, Sustainable Technology Division, Systems Analysis Branch, Cincinnati, OH, USA.

${ }^{\text {e}}$ CIRAIG, Department of Chemical Engineering, Polytechnique Montréal, Montréal, Canada.

${ }^{\mathrm{f}}$ Industrial Ecology Programme, Department of Energy and Process Engineering, Norwegian University of Science and Technology, Trondheim, Norway

${ }^{\mathrm{g}}$ School of Public Health, University of California, Berkeley, CA, USA.

${ }^{\mathrm{h}}$ NTNU Sustainability, Norwegian University of Science and Technology, NO-7491 Trondheim, Norway

${ }^{\mathrm{i}}$ United Nations Environment Programme, Division of Technology, Industry and Economics, Paris, France.

${ }^{\mathrm{j}}$ ETHZ - Swiss federal institute of technology - Zurich, Switzerland

${ }^{\mathrm{k}}$ Commonwealth Scientific and Industrial Research Organisation (CSIRO), Private Bag 10, Clayton South, Victoria 3169, Australia; and University of the Free State, Department of Agricultural Economics, Bloemfontein 9300, South Africa

${ }^{1}$ Irstea, UMR ITAP, ELSA Research group \& ELSA-PACT-Industrial Chair for Environmental and Social Sustainability Assessment, 361 rue J.F. Breton, 5095, 34196 Montpellier, France

${ }^{\mathrm{m}} \mathrm{SETAC}$, Pensacola, FL, USA.

${ }^{\mathrm{n}}$ School of Public Health, Environmental Health Sciences, University of Michigan, Ann Arbor, MI, USA.

\begin{abstract}
Purpose The life cycle impact assessment (LCIA) guidance flagship project of the UNEP/SETAC Life Cycle Initiative aims at providing global guidance and building scientific consensus on environmental LCIA indicators. This paper presents the progress made since 2013, preliminary results obtained for each impact category, and the description of a rice life cycle assessment (LCA) case study designed to test and compare LCIA indicators.
\end{abstract}

Methods The effort has been focused in a first stage on impacts of global warming, fine particulate matter emissions, water use and land use, plus cross-cutting issues and LCA-based footprints. The paper reports the process and progress and specific results obtained in the different task forces (TF). Additionally, a rice LCA case study common to all TF has been developed. Three distinctly different scenarios of producing and cooking rice have been defined and underlined with life cycle inventory data. These LCAs help testing impact category indicators which are being developed and/or selected in the harmonisation process. The rice LCA case study further helps to ensure the practicality of the finally recommended impact category indicators.

Results The global warming TF concludes that analysts should explore the sensitivity of LCA results to metrics other than GWP. The particulate matter TF attained initial guidance of how to include health effects from $\mathrm{PM}_{2.5}$ exposures consistently into LCIA. The biodiversity impacts of land use $\mathrm{TF}$ suggests to consider complementary metrics besides species richness for assessing biodiversity loss. The water use TF is evaluating two stress-based metrics, AWaRe and an alternative indicator by a stakeholder consultation. The cross-cutting issues TF agreed upon maintaining DALY as endpoint unit for the safeguard subject "human health". The footprint TF defined main attributes that should characterise all footprint indicators.

"Rice cultivation" and "Cooking" stages of the rice LCA case study contribute most to the environmental impacts assessed.

Conclusions The results of the TF will be documented in white papers and some published in scientific journals. These white papers represent the input for the Pellston workshop ${ }^{\mathrm{TM}}$, taking place in Valencia, Spain from 24 to 29 January 2016, where best practice, harmonised LCIA indicators and an update on the general LCIA framework will be discussed and agreed on. With the diversity in results 
and the multi-tier supply chains the rice LCA case study is well suited to test candidate recommended indicators and to ensure their applicability in common LCA case studies.

Keywords: Life Cycle Impact Assessment, LCIA, impact indicators, footprint, guidance, rice cultivation

\section{Introduction}

\subsection{Global guidance on LCIA indicators}

Phase 3 of the UNEP-SETAC Life Cycle Initiative (2012-2017) has launched a flagship project to provide global guidance and build consensus on environmental Life Cycle Impact Assessment (LCIA) indicators (see http://www.lifecycleinitiative.org/ under the Phase 3 activities for the full list of projects). Following initial scoping workshops in 2012 and 2013 and a stakeholder consultation, the effort has been focused in a first stage on impacts of global warming, fine particulate matter, water use impacts and land use impacts on biodiversity (Jolliet et al. 2014), plus cross-cutting issues and LCA-based footprints. A first Pellston workshop ${ }^{\mathrm{TM}}$ is planned for January 2016 to issue recommendations for these categories ${ }^{1}$. In a second stage the project will address human toxicity, acidification, eutrophication, ecotoxicity, and energy resources. It will also provide recommendations on how to integrate these individual indicators in a consistent framework, ensuring consistency of indicator selection process and assessment across impact categories. The deliverables will include a global guidance publication with a supporting web-based system that contains the finally selected LCA based environmental impact category indicators and characterisation factors (for various regions), which will be available for viewing and download.

\subsection{Objective of the present paper and outline}

The aim of the present paper is two-fold: a) Report the process and progress made and the preliminary results obtained in each impact category (see Section 2), and b) Present and document a worldwide rice LCA case study to be used to test and compare Life Cycle Impact Assessment indicators across impact categories (see Section 3). Section 4 contains first conclusions from the work of the task forces and the rice LCA case study.

\section{Progress and achievements per task force and impact category}

\subsection{Introduction}

This section contains a description of the goals of the various task forces, the process and progress made since the start of this flagship project as well as first results achieved so far. First the flagship project as a whole is described, followed by the task forces global warming, fine particulate matter, biodiversity impacts of land use, impacts of water use, cross-cutting issues and finally LCA based footprint indicators.

\subsection{General guidance and coordination (Rolf Frischknecht, Olivier Jolliet)}

Goal: The goal of this flagship project is to run a global process aiming at global guidance and consensus building on a limited number of environmental indicators. The global process involves more than 100 world leading environmental and LCA scientists, organized in impact category specific task forces (TFs) and complemented by a cross-cutting issue TF to develop scientifically robust indicators suitable for a global consensus. The first phase of the consensus-finding process will end with a Pellston workshop ${ }^{\mathrm{TM}}$, a one week workshop that will take place in Valencia, Spain from 24 to 29 January 2016, where invited experts and stakeholders aim to agree on recommended environmental indicators.

\footnotetext{
${ }^{1}$ A Pellston workshop ${ }^{\mathrm{TM}}$ is an intensive, week-long event format developed by the Society of Environmental Toxicology and Chemistry (SETAC) in the 1970's. Each of the more than 50 such workshops held to date has adhered to the same structure, format, and ground rules. Among these are the requirements that each of the invited participants agrees to engage as an individual expert, not as a representative of an organization, participate for the entire duration, contribute to a major publication derived from the effort, and respect the consensus building process employed during the conduct of the workshop. SETAC Pellston workshops ${ }^{\mathrm{TM}}$ have produced seminal publications across a variety of environmental science topics and issues, including five such publications on LCA.
} 
Process and progress: Following the paper presenting and scoping the LCIA guidance flagship project (Jolliet et al. 2014), coordination and continuous project monitoring was carried out involving all TF co-chairs by monthly teleconferences and standard forms enabling each task force to report technical content, timeline and memberships. The achievements made by each TF are described in more details in each subsection of the present paper. The first milestones in 2014 and 2015 have been the set-up of multiple LCIA guidance workshops in Basel (15-16 May 2014), Adelaide (15 September 2014) and Barcelona (7-8 May 2015). These workshops enabled each task force to get feedback from multiple stakeholders, to address specific critical cross cutting issues and key points for guidance on Life Cycle based footprints.

Results: The Pellston workshop ${ }^{\mathrm{TM}}$ proposal as well as the steering committee composition has been approved by SETAC and by the International Life Cycle Board of the UNEP-SETAC Life Cycle Initiative. Guidance on Life Cycle based footprinting will remain part of the flagship project, but treated separate from the Pellston workshop ${ }^{\mathrm{TM}}$ that will focus on the LCIA indicators recommendations. The steering committee convened in a meeting at SETAC Barcelona for the members attending the congress, as well as via three teleconferences on 19.6, 23.6 and 9.7. Main outcome of the steering committee activity is an initial list of 48 foreseen participants to the Pellston workshop $^{\text {TM }}$ coming from 15 different countries, ensuring representation of the different continents, sectors and TFs. Finally, the development of a cross TF rice LCA case study has been finalized in collaboration with the particulate matter (PM) TF to facilitate impact category-specific model comparisons and testing. This rice LCA case study is further detailed in Section 3 of this paper.

\subsection{Global Warming (Annie Levasseur, Francesco Cherubini)}

Goal: Global warming is considered as having a high environmental relevance among life cycle impact assessment (LCIA) categories. Global Warming Potential (GWP), i.e. the cumulative radiative forcing caused by a greenhouse gas (GHG) emission over an arbitrary time horizon (TH, e.g., 20, 100 or 500 years) relative to that of $\mathrm{CO}_{2}$, is the most common metric used in LCA to group the climate impacts from GHGs into $\mathrm{CO}_{2}$-equivalents, a mid-point indicator. As global warming causes impacts on both human health and biodiversity, some LCIA methods also provide end-point indicators to assess those impacts.

The goal of the global warming TF is to propose guidelines for the development of characterisation factors for the global warming impact category, and to identify research needs in this area. Building on the Chapter 8 of the IPCC (Intergovernmental Panel on Climate Change) 5th Assessment Report for Working Group I Myhre et al. 2013, a systematic analysis of available emission metrics and characterisation methods for the various climate forcing agents is first performed. Discussion involves data sources, modelling conditions, and temporal/geographical scope among others.

Process and progress: The global warming TF is composed of 13 scientists having complementary expertise in climate modelling, climate metrics and/or global warming impact assessment in LCA. Two subtask forces have been established to work on specific issues, using the 5th Assessment Report of IPCC IPCC 2013 as the basic source of knowledge: 1) well-mixed greenhouse gases and near-term climate forcers (NTCFs), 2) biogeophysical climate forcings from land use and land cover changes.

The global warming TF focused on drafting peer-reviewed articles presenting the outputs of its activities. Preliminary recommendations are given in a paper entitled: "Updating life cycle impact assessment from climate science: midpoint indicators".

Chapter 8 of the last IPCC report states that "the most appropriate metric will depend on which aspects of global warming are most important to a particular application, and different climate policy goals may lead to different conclusions about what is the most suitable metric with which to implement that policy" Myhre et al. 2013. LCA traditionally aggregates emissions of well-mixed greenhouse gases to so-called " $\mathrm{CO}_{2}$-equivalents" using GWP100 as the default emission metric. GWP was introduced by the first IPCC assessment report in 1990 with illustrative purposes and does not embed any climate system responses or direct link to policy goals Shine 2009. GWP100 was perceived to align well with the general principles of LCA, which privileges impacts integrated over time and space. An alternative to GWP shown in the $5^{\text {th }}$ IPCC Assessment Report is the Global Temperature Change Potential (GTP), which is defined as the impact of a GHG emission pulse on global temperature at the chosen $\mathrm{TH}$, again relative to $\mathrm{CO}_{2}$. Values of GTP for a TH of about 40 years are usually similar to those of GWP100. The choice between GWP100 and GTP100 can thus be seen as a preference to reduce global 
warming over the next few decades (GWP100) or in a longer period (GTP100). Another option is the integrated GTP (iGTP), which is based on the integrated impact on global temperature of an emission pulse and yields characterization factors similar to GWP. In general, aggregating species with significant different atmospheric lifetimes to common units is challenging Myhre et al. 2013. In these cases, the choice of the metric and the TH crucially matters for the importance given to forcers with a relatively short lifetime of up to a few decades, like $\mathrm{CH}_{4}$, compared to very long-lived forcers, like $\mathrm{CO}_{2}$.

Human activities perturb the climate system also through emissions of pollutants such as $\mathrm{NO}_{\mathrm{X}}, \mathrm{SO}_{\mathrm{X}}$, black carbon (BC), and others. These species have lifetimes shorter than the hemispheric mixing time and are usually called near-term climate forcers. The atmospheric concentrations of NTCFs are very heterogeneous and the resulting impact largely depends on the source region. The consideration of NTCFs in LCA should be cautious. Their impacts at local scale can differ from those averaged globally, some of them have cooling contributions (calling for a consistent treatment of negative characterization factors across impact categories) and their impacts on climate have a confidence level that is lower than that for GHGs, especially in the cases in which aerosol-cloud interactions are important Myhre et al. 2013. Changes in land use or land cover also cause impacts on climate. In addition to possible emissions of GHGs, changes in surface albedo (the ratio between reflected and incident solar radiation at the surface) have direct global climate implications, which are usually of opposite sign to those of $\mathrm{CO}_{2}$. Albedo changes can be converted to $\mathrm{CO}_{2}$ equivalents using either carbon equivalent factors or conventional emission metrics like the GWP or GTP Cherubini et al. 2013; Caiazzo et al. 2014.

The Global Warming Task Force argues for an active consideration of these issues by the LCA community. The choice of one metric over another and the inclusion or exclusion of certain forcing agents can have large effects on the final LCA results, with the ultimate risks to identify mitigation options that are suboptimal, if not counterproductive.

Results: The TF concludes that the LCA methodology should gradually move towards the use of several sets of CFs based on different metrics and/or time horizons so that analysts can test the sensitivity of conclusions to such choices. A step-by-step approach is recommended consisting briefly in selecting a few metrics and time horizons, calculating impact scores, and communicating about the meaning and impact of modelling choices if conclusions vary. Preliminary recommendations are: a) to use midpoint metrics which include climate-carbon feedbacks for $\mathrm{CO}_{2}$ and all well mixed greenhouse gases, b) to quantify the impact including and excluding near-term climate forcers to determine whether or not their inclusion changes conclusions, and c) provide uncertainty estimates with the characterization factors ${ }^{2}$. In the TF paper, the pros and cons of each choice will be clearly presented and discussed so to ensure informed decisions by LCA practitioners.

During the plenary meeting in Barcelona, there were expressions of concerns for departing from cumulative metrics in LCA. In an LCA context, cumulative metrics like GWP or iGTP can ensure consistency across impact categories, while GTP is a special case as it is an instantaneous indicator. Future research can explore the feasibility within the LCA framework of better assessing the temporal and spatial heterogeneities of the various climate impact dynamics, for instance via time-distributed indicators (in terms of radiative forcing or temperature profiles) and subglobal impact categories (to be ideally addressed in combination with the regionalization efforts in other environmental impact categories).

\subsection{Particulate matter (Tom McKone, Peter Fantke)}

Goal: Fine particulate matter $\left(\mathrm{PM}_{2.5}\right)$ is one of the most important environmental factors contributing to the global human burden of disease. However, different models are currently used leading to inconsistent life cycle impact assessment results reported for this category, thereby emphasizing the need for a clear guidance for practitioners. To address this need, a TF was initiated to build a health

\footnotetext{
${ }^{2}$ The inclusion of GWP values for NTCFs in life cycle impact assessment will substantially increase the uncertainty associated to GWP values. The global warming impact of non fully mixed pollutants with short lifetime depends on local short-term processes that are very complex to model and vary depending on the location of emission. The IPCC 5th assessment report does not provide consolidated GWP or GTP values for these NTCFs but compiles the findings of various scientific research and publications (see IPCC 2013, Section 8.7.2.2 and Tab. 8.A.3 to Tab. 8.A.6).
} 
impact framework and factors for $\mathrm{PM}_{2.5}$ and its precursors. The TF will harmonize existing tools and methods, and determine recommended factors for various source and exposure archetypes, incorporating human health effects from $\mathrm{PM}_{2.5}$ outdoor and indoor releases in LCIA.

Process and progress: The TF is sub-divided into three subtask forces working on (1) indoor intake fractions, (2) outdoor intake fractions, and (3) exposure-response functions, respectively. The common rice LCA case study and cross-cutting issues as well as a final framework for combining results and recommendations from all three groups are jointly assessed by all groups. The TF started with an expert workshop in Basel, Switzerland, in August 2013 to get initial guidance of how to address including health effects from $\mathrm{PM}_{2.5}$ exposures consistently into LCIA. The outcome of this initial guidance workshop was complemented by a literature review of the state of the knowledge in $\mathrm{PM}_{2.5}$ exposure assessment. Fantke et al. 2015 provide the workshop findings compiled into a set of preliminary recommendations for addressing $\mathrm{PM}_{2.5}$ related health effects in LCIA. A second workshop was held in Cincinnati in October 2014 to address cross-cutting issues between indoor intake fraction, outdoor intake fraction and exposure-response. TF progresses and results were in addition reported in several conferences at SETAC-Europe, SETAC North-America and ISES (International Society for Exposure Science) annual meetings.

Results: The indoor subgroup has reviewed and identified a set of factors (ventilation rate, room volume, occupancy, inhalation rate, time-activity patterns, particle penetration efficiency, deposition, filtration, phase changes and indoor chemistry, and finally emission sources) influencing indoor inhalation intake of $\mathrm{PM}_{2.5}$ and an inventory of available approaches to be evaluated in a model comparison Hodas et al. 2015. Indoor models are currently being compared for different archetypes (buildings with only mechanical air exchange, closed buildings with natural ventilation, open buildings with high-ventilation rate in tropical area, and one-path vs. recirculated ventilation) and integrated with outdoor intake into a consistent and comprehensive framework to assess impacts of $\mathrm{PM}_{2.5}$ exposure indoors and outdoors. The exposure-response group performed the analysis of potential exposure-response curves, building on the work of Apte et al. 2015 and the exposure response curves used in the global burden of Disease Burnett et al. 2014. Three possible exposureresponses options have been considered, illustrated by a comparison between US and China: derivative at regional working point, slope from regional working point to zero or fixed slope based on reference situation. Next step is to analyse the consequences of each of these options on the estimates of impacts on human health caused by $\mathrm{PM}_{2.5}$ emissions as reported in the different scenarios of the rice LCA case study (see section 3).

\subsection{Biodiversity impacts of land use (Ottar Michelsen, Assumpció Antón, Llorenç Milà i Canals)}

Goal: An intensive transformation of natural areas over the last decades has caused the loss of important environmental assets. Land use and particularly land use change from natural habitats to cropland and other human dominated land cover types, as well as fragmentation of habitats, are among the main drivers of biodiversity loss and degradation of a broad range of ecosystem services. Considering the manufacturing and production activities of human society as some of the main drivers to land use and land use change, there is the need to focus on the prediction of potential impacts, such as biodiversity loss. No clear consensus exists yet on the use of (a) specific impact indicator(s) to quantify land use impacts on biodiversity within LCA. To address this gap, a TF on the quantification of land use impacts on biodiversity within LCA was initiated. This TF aims at global guidance and consensus regarding indicators and methods for the assessment of biodiversity impacts from land use (and, if possible, land use change) in LCA.

Process and progress: The TF on impacts on biodiversity from land use has developed an updated list of criteria for the evaluation of existing methods, which has been applied to 30 methods. Following a start-up workshop to frame the evaluation criteria in Basel (15 May 2014), multiple expert workshops and stakeholder consultations took place in 2014 (San Francisco, USA, 7 October 2014: focus on importance of evaluation criteria and choice of indicators; Brussels, Belgium, 18-19 November 2014: focus on evaluation criteria and usability of methods; Sao Paulo, Brazil, 12 November 2014: Stakeholder consultation on indicators for biodiversity in LCA). The TF is currently collaborating with the crosscutting issues TF on defining ecosystem quality. 
Results: The review and evaluation task has highlighted the diversity of approaches towards characterising biodiversity change Teixeira et al. 2015. Currently, taking a conservative view, only two (three) methods could be operational for practitioners of LCA at a global scale: de Baan et al.2013 which is further developed in Chaudhary et al. 2015, and Coelho and Michelsen 2014, but they may not be well suitable to catch specificity of rice production as well as different intensiveness of agricultural practices. In addition, there are several doubts about regional representativeness of biodiversity damage (see rice LCA case study in section 3). A number of other models could be adapted to LCA with relatively little effort to provide either local or regional characterisation factors on a global scale, but there will be challenges in extracting the meaningful data from these models and combining them in a meaningful way to develop consensus based characterisation factors at both the local and regional level Teixeira et al. 2015. The experts highlighted the importance of the procedure established by the Life Cycle Initiative, including the early engagement of stakeholders in the consensus-building process. Experts agree that LCA may go beyond inventory data for land use (LU)/ land use change (LUC) and relate elementary flows to their respective impacts on biodiversity. Local biodiversity loss due to LU/LUC typically requires a level of spatial resolution and farm-specific knowledge for which other non-LCA tools may be more accurate. It was also agreed that a good LCA indicator for biodiversity necessarily has to include geographical location, several aspects that depict the state of ecosystems at that location, and a measure of intensity. Species richness is a good starting point for assessing biodiversity loss, an indicator often used by LCIA developers. However, complementary metrics are suggested to be considered in modelling, such as habitat configuration, including fragmentation and vulnerability, and/or intensity-based indicators (NPP/HANPP).

\subsection{Water use (Anne-Marie Boulay, Stephan Pfister)}

Goal: Since the consensus framework defining impact assessment of water use in LCA was published in 2010 Bayart et al. 2010, several impact assessment methods were developed, assessing impacts on human health, ecosystem quality or resource depletion. Water is also gaining importance and attention as an area of concern and impact category, and stakeholders are often asked to communicate on their water use impacts in a single and simple metric. Among LCA practitioners, there is a need for a harmonized set of indicators assessing impacts from water use, both at the midpoint and endpoint levels, including one simple scarcity/stress-based metric providing an alternative to the more complex damage-oriented methods. The TF therefore focuses on the development of such a consensual stressbased metric in addition to harmonized damage-oriented impact pathways for human health and ecosystem quality.

Process and progress: The water use TF (WULCA) presently has three active subtask forces. The stress subtask force has collected input from more than 50 experts via workshops held on three continents: in Zurich, Switzerland, San Francisco, USA and Tsukuba, Japan Boulay et al. 2014, followed by an additional expert meeting held in April 2015 via teleconference, to provide preliminary recommendations Boulay et al. 2015, which were presented in May 2015 at the SETAC Conference in Barcelona. The human health subgroup held one expert workshop in Barcelona, with representatives of Food and Agricultural Organization (FAO), World Resource Institute (WRI), as well as scientists and consultants. The main modelling challenges were discussed and will guide preliminary decisions on the modelling of this impact pathway. The ecosystem quality subgroup started framework discussions and plans to recommend methods in the next phase.

Results: The pre-recommended method by the stress subtask force is called AWaRe. This water use midpoint indicator is based on the relative Available WAter Remaining in a watershed, after the demand of humans and aquatic ecosystems has been met. It is first calculated as the water availability minus the demand (humans and aquatic ecosystems) per unit area of the considered region $\left(\mathrm{m}^{3} \mathrm{~m}^{-2} \mathrm{yr}^{-}\right.$ $\left.{ }^{1}\right)$. This ratio is then inverted and hence represents the area "virtually occupied" to cover the additional water consumption in a sustainable manner. In a second step, the value is normalized by the world average value in order to provide the regionally available water remaining relative to the world consumption-weighted average of this value. The indicator ranges from 0.1 to 100 , with a value of 1 corresponding to the world average, and a value of 10, for example, represents a region where there is 10 times more area required to provide $\mathrm{a} \mathrm{m}^{3}$ of water sustainably than the world average. Or in other terms there is 10 times less water available on the same area compared to the world average. The 
indicator is calculated at the sub-watershed level and monthly time-step, and then aggregated to country and annual resolution. This aggregation can be done in different ways to better represent either an agricultural use or a domestic/industrial use, based on the time and region of water use. Characterisation factors on annual and country level for agricultural and non-agricultural use are therefore provided separately, as it implies different spatio-temporal aggregation. This method quantifies the potential of water deprivation, to either humans or ecosystems, and serves in calculating a water scarcity footprint according to ISO 14046, clause 5.4.5. The group is still also testing an alternative indicator combining demand-to-availability and area-to-availability ratios in view of the final recommendation. These two indicators are currently undergoing a stakeholder consultation. For the sub-group human health no pre-recommendations are available yet, but it is agreed that Motoshita et al. 2014 will be used as a starting point and focus on additional methodological improvements to make the method more robust as well as add a domestic user deprivation module. More complex approaches have been analysed and discussed (improved economic models, differentiating water source and quality) but do not seem yet mature enough for this global consensus (limited time for complex development, and low quality of available data).

\subsection{Cross-cutting issues (Francesca Verones)}

Goal: In addition to providing recommendations for specific life cycle impact assessment category indicators, it is important that individual indicators are consistent and integrated in a comprehensive framework. The cross-cutting issues TF therefore aims to continue research and development on the LCIA framework and to provide guidance on issues relevant for all impact categories such as spatial differentiation, uncertainty, etc. It will produce a guidance document on how to best reach consensus, ensuring consistency of indicator selection process and assessment approaches across impact categories.

Process and progress: The TF started its work in January 2015, with 10 active sub-tasks defined (framework, human health, ecosystem quality, resources, spatial aspects, normalization, uncertainties, temporal aspects, relationships between social LCA and biophysical indicators and the overall consensus finding). The whole TF has had monthly teleconferences, where progress is presented and feedback is given. In between the teleconference, each sub-task, led by different people, has worked on the relevant questions and problems. One physical meeting took place on 7 May, 2015, following the SETAC conference in Barcelona.

Results: Preliminary recommendations have been agreed upon for several sub-tasks and main lines of thoughts have been developed further at the Barcelona workshop. For human health, it was agreed upon to maintain DALY (Disability Adjusted Life Years) as endpoint unit, acknowledging that this contains already a (internationally well accepted) weighting. For ecosystem quality, the preliminary recommendation is to have "species disappearance" as endpoint. This implies selecting a PDF/PAF (Potentially disappeared/affected fraction of species) based metric. There are however different PDF/PAF based approaches, thus the importance to ensure compatibility. Other endpoint units are also an option, as long as a conversion to PDF/PAF is possible. The main line of thought is that the species extinction we aim to capture at the endpoint level should be quantifiable for any region of the world and should also account in some way for the vulnerability of the respective ecosystems and species assemblages. How such a vulnerability indicator should look like is an object of further investigation. In most topics, multiple research activities are ongoing, in- and outside of the TF and it is important to build framework and recommendations in a compatible way that may incorporate future developments. We therefore need to distinguish immediate recommendations from future ones: It might for example be advantageous in the future to split "ecosystem quality" into a more anthropocentric "ecosystem services" and an "ecosystem well-being" (ecosystems and biodiversity in their own right) category. However, such a recommendation cannot be made at this stage, due to the present lack of operational methodologies.

\subsection{Footprint indicators (Brad Ridoutt)}

Goal: The proposed goal of this activity is a) to form a common understanding of the differences between footprints and existing LCA impact category indicators, b) to formalise a universal definition of an LCA-based footprint, and c) to achieve consensus about acceptable ways of calculating LCAbased footprints which address Area of Concern in parallel with Area of Protection, Outputs are in the 
form of guidance documentation intended for developers of LCA-based footprints. The scope of the work is not to define specific footprint indicators, or to define a specific list of footprint indicators. The scope is to provide global guidance to enable the development of LCA-based footprints which address any Area of Concern (AoC) - defined now or in the future according to end-user demand. Area of Concern is an environmental topic defined primarily by the interests of stakeholders and the community.

Process and progress: This TF was established in March 2014 and a statement on goal and scope was drafted that same month. Multiple teleconferences, presentations and meetings took place in particular in Basel (15/16 May 2014), Adelaide (15 September 2014) and a first seed document was circulated for which more than 100 comments were received. Consensus was reached in resolving the comments on the seed document during a face-to-face TF meeting in San Francisco (8 October 2014) and various teleconferences and has led to an initial scientific paper Ridoutt et al. 2015b. Liaison is also ensured with ISO TC207/SC3/WG6 which is developing a new international standard on footprint communications (ISO 14026). Key elements of the UNEP-SETAC Life Cycle Initiative's work have already been adopted in the ISO 14026 Working Draft. Following a further face-to-face TF meeting in Barcelona (8 May 2015), a second paper has been accepted for publication which introduces the universal footprint definition and related terminology and includes a discussion of some of the modelling implications Ridoutt et al. 2015a.

Results: The initial work undertaken by this TF involved forming a consensual understanding of the difference between footprint indicators and existing LCA impact category indicators. Without differentiation, footprints serve no additional purpose in LCA. In short, footprints have a primary orientation toward society and nontechnical stakeholders and report on only selected topics of societal concern. On the other hand, LCA impact category indicators have a primary orientation toward stakeholders interested in a comprehensive evaluation of environmental performance and trade-offs.

While LCA reports and footprints may serve different purposes, the TF work has underscored the importance of LCA inventory and impact assessment modelling as the basis for footprint calculations. To avoid confusion and contradictions, footprints should provide guidance for decision-making which is coherent with LCA results of equivalent scope. For example, a water footprint should deliver results which are consistent with LCA indicator results pertaining to water use. This issue highlights the importance of this TF's work. Currently, there is a proliferation of footprints, many of which report results which are inconsistent with those of LCA studies, leading to contradictory messages in the marketplace Ridoutt and Huang 2012; Ridoutt et al. 2012; Pfister and Ridoutt 2013, and a reluctance to apply footprinting and LCA methods in many public policy and business contexts.

So far, the TF has reached consensus on four defining attributes that should characterise all footprint indicators: environmental relevance, accurate terminology, directional consistency and transparent documentation, as described by Ridoutt et al. 2015b. Recognising the differences in purpose and orientation between footprints and LCA study reports, the TF is now working towards consensus on technical issues relating to footprints which may deviate from conventional practices in LCA. One such issue is double counting. In LCA, emphasis is placed on avoiding double counting between indicators when reporting a profile of impact category indicators. However, when reporting a profile of footprints, some forms of overlap of impacts may be permissible in order to make individual footprints comparable between products. For example, if a product reported two footprints, a water footprint and a toxicity footprint, some water-related toxicity impacts might be reported in both. The plenary meeting in Barcelona emphasized that the shares of footprint contributions in combined footprints must be identified and declared. With this measure potential overlaps can easily be identified by the users of the information. The important consideration with footprints, with their orientation toward society and nontechnical stakeholders, is that they should be able to be interpreted without consulting technical study reports. These and other matters are to be discussed in a forthcoming scientific article.

\subsection{How to ensure practicality of harmonised LCIA indicators}

The task forces working on a harmonisation of environmental life cycle impact assessment indicators will apply several of them in the impact assessment phase of a common LCA case study. This case study should represent a common LCA as performed today and thus contain the key elements to take 
into account when recommending one particular indicator. The following section described the case study developed within this flagship project.

\section{Rice case study to test life cycle impact category indicators}

\subsection{Introduction and overview}

The rice LCA case study serves as a test application for the environmental life cycle impact category indicators developed and recommended by the TFs of this UNEP SETAC life cycle initiative flagship project.

The case study is not meant to be fully representative for rice production and consumption in the regions covered but should serve as a test environment and ensure the applicability of the harmonised life cycle impact category indicators developed within this flagship project in common LCA studies and background LCA databases.

The rice LCA case study deals with the supply chain of cooked white rice from the agricultural field to the cooking pot covering three different regions in three scenarios:

- Urban China: Rice production and processing in rural China, distribution and cooking in urban China

- Rural India: Rice production, processing, distribution and cooking in rural India

- US-Switzerland: Rice production and processing in the USA, distribution and cooking in Switzerland.

Each scenario covers the four life cycle stages: farm production, processing, distribution and cooking as shown in Figure 1. The functional unit (FU) is $1 \mathrm{~kg}$ of cooked white rice consumed at home as most frequently selected in LCA studies of rice production systems Blengini and Busto 2009; Brodt et al. 2014; Fusi et al. 2014; Hokazono and Hayashi 2012. The complete case study inventories are explained in detail in the supplementary material.

\subsection{Life cycle stages}

Farm production: The "Farm production" stage includes all field operations for rice production from cradle to farm gate. The use and production of fertilizers, pesticides and diesel for field management practices are incorporated in addition to their direct emissions. Furthermore, direct land occupation and the quantity of water withdrawn and evaporated have been accounted for. It is assumed that straw is incorporated into the soil (soil improvement). So paddy rice is the only product and no allocation is needed (in accordance with Blengini and Busto 2009; Brodt et al. 2014; Fusi et al. 2014.

Processing: The "Processing" stage includes the transportation of paddy rice from the farm to the next rice processing plant, dehusking and milling (processing) of rice, as well as primary packaging of the refined rice (internal plastic bag and external cardboard box).

During the processing of raw rice, rice husks and rice bran are generated as co-products. Rice husks are commonly used as bedding materials, animal feed or energy source for rice grain drying, parboiling and for electricity generation ${ }^{3}$. Rice bran serves as an excellent binder and ingredient for animal feed ${ }^{4}$. Table 1 shows the prices and volume fractions of the co-products of white rice. This information is used to apply an economic allocation, in which white rice receives an allocation factor of 0.94 , rice bran 0.05 and rice husk 0.01 .

Distribution: Distribution includes both the transport of the refined rice from the processing plant to the point of sale, and the transport by the consumer from the point of sale to home. Rice is commonly stored in bulk containers with a payload of 21.6 tons each. Therefore, a lorry with a carrying capacity of more than 32 tons is required.

\footnotetext{
${ }^{3}$ http://www.knowledgebank.irri.org/step-by-step-production/postharvest/milling\#by-products_Accessed on April $13^{\text {th }}, 2015$

${ }^{4}$ http://www.knowledgebank.irri.org/step-by-step-production/postharvest/milling\#by-products_Accessed on April $13^{\text {th }}, 2015$
} 
Cooking: Cooking includes country-specific cooking operations at home. $1 \mathrm{~kg}$ of cooked rice requires $0.7 \mathrm{~kg}$ of parboiled white rice, 1.1 (China and Switzerland) and 1.7 litre (India) of water and 5 to 10 grams of table salt. The table salt is disregarded in any of the three scenarios and not part of the product system analysed.

\subsection{Scenarios}

Introduction: The following subsections include a description of the three scenarios of the rice case study. Life cycle inventory data stem from the ecoinvent data v2.2, from the Agri-footprint database and from working and scientific papers Jungbluth 1997; Singh et al. 2014. All data were harmonised as far as possible and embedded into the ecoinvent data v2.2. Table 2 summarizes the key characteristics of the three scenarios.

Urban China: The province of Hunan, the top rice production province in China, is chosen as the rice producing area. It exports most of its surplus to other provinces. Most of Hunan's arable land is farmed using modern techniques, including mechanized irrigation and chemical fertilization ${ }^{5}$. It is estimated that most of the province's cultivable land is devoted to paddies (wet-rice fields), a great many of which are flooded by river systems during most of the year ${ }^{2}$. The rice yield stated in Table 2 $(6450 \mathrm{~kg} / \mathrm{ha})$ equals China's average rice yield, which is among the highest in Asia ${ }^{6}$ Blonk Agrifootprint BV 2014. According to this source, about $27 \mathrm{~g}$ methane is emitted per $\mathrm{kg}$ of rice produced. The average amount of water needed for Chinese rice production includes irrigation water withdrawn from water wells and river water run-off Chapagain and Hoekstra 2011.

Once raw rice is harvested, it is transported to Chenzhou, a city in the province of Hunan by a lorry complying with an emission standard equivalent to EURO III, which was nationwide implemented in $2007^{7}$. After dehusking and milling, white rice is packed and transported to a supermarket in Shanghai covering a distance of $1300 \mathrm{~km}$ (see Table 2).

In China it is common to buy rice in $10 \mathrm{~kg}$ bags. Hence, for this scenario it is assumed that one bag of rice of $10 \mathrm{~kg}$ is bought per shopping trip in a supermarket in Shanghai and carried home by public bus ( $6 \mathrm{~km}$ both ways). In China rice is mostly cooked in electric rice cookers. Besides $0.7 \mathrm{~kg}$ of white rice, 1.11 of water is added for cooking.

Rural India: The State of West Bengal is India's top rice production state and produces almost $16 \%$ of India's total rice ${ }^{8}$. Hence, West Bengal is the rice production area selected for this scenario. The rice yield in India amounts to 3'500 kg/ha OECD/FAO 2014, which is a bit more than half of China's average rice yield (see Table 2). Therefore, more land is occupied to produce $1 \mathrm{~kg}$ of rice and hence more diesel for agricultural machines is assumed to be used (larger areas to cultivate). The amount of water withdrawn per $\mathrm{kg}$ rice depends on the cultivation method and irrigation regime applied Shantappa et al. 2014. According to Chapagain and Hoekstra 2011 the irrigation water withdrawn from ground- and surface water per kg paddy rice sums up to $1.435 \mathrm{~m}^{3}$ in India. Furthermore, biogenic methane emissions play an important role in the paddy rice production. In India $30 \mathrm{~g}$ methane is emitted per kg of rice produced ${ }^{9}$.

The harvested rice is transported by lorry to the relatively small city of Contai, in the State of West Bengal. Since 2000, also India started adopting emission and fuel regulations for light- and heavy-duty vehicles. Bharat Stage III is required since 2010 nationwide ${ }^{10}$. Even though the Bharat standard does not seem to include smoke threshold levels it is regarded as equivalent to EURO III $^{6}$.

After processing, the rice is transported to Kolkata, the capital of the State of West Bengal, which is only a $150 \mathrm{~km}$ drive away from Contai. In contrast to the urban China scenario, the consumer in India is assumed to use a bicycle to go to a supermarket located $1.5 \mathrm{~km}$ away from home and buys a $10 \mathrm{~kg}$ bag of white rice (see Table 2).

In rural areas of West Bengal $74 \%$ use firewood for cooking while in urban areas only $14 \%$ use firewood TERI 2013. They use open three-stone stoves for indoor cooking with firewood. Cooking

\footnotetext{
${ }^{5}$ http://www.britannica.com/EBchecked/topic/276448/Hunan/71286/Agriculture Accessed on April $1^{\text {st }}, 2015$

${ }^{6}$ http://irri.org/our-work/locations/china Accessed on April 13 ${ }^{\text {th }}, 2015$

${ }^{7} \mathrm{https}: / /$ www.dieselnet.com/standards/cn/hd.php Accessed on April 1 ${ }^{\text {st }}, 2015$

${ }^{8}$ http://sbbri.com/indianrice.html Accessed on April 6 ${ }^{\text {th }}, 2015$

${ }^{9} \mathrm{http}$ ://faostat3.fao.org/compare/E. Accessed on April 6 ${ }^{\text {th }}, 2015$

${ }^{10}$ https://www.dieselnet.com/standards/in/hd.php Accessed on April 1 ${ }^{\text {st }}, 2015$
} 
with firewood has a low efficiency, generates a high amount of particulate matter (PM) emissions and uses about $50 \%$ more water than when cooking with an electric cooker ${ }^{11}$ (Singh et al., 2014).

USA - Switzerland: Arkansas records the highest rice production in the US ${ }^{12}$. This is why the third scenario focuses on that area for rice production with an average US rice yield of $7^{\prime} 452 \mathrm{~kg} / \mathrm{ha}$ Nemecek et al. 2007. According to this source, about $41 \mathrm{~g}$ methane is emitted per kg of rice produced. The processing plant is assumed to be in Little Rock, Arkansas. The US EPA and California Emission Standards for heavy-duty vehicles applicable from 2007 are tougher and thus set lower acceptable threshold levels (measured in grams per brake horsepower-hour) with regard to $\mathrm{NO}_{\mathrm{X}}, \mathrm{PM}$ and $\mathrm{HC}$ emissions than the EURO VI emission standard ${ }^{13}$. Taking the average age of a US lorry into account, a lorry with emission standard EURO V is considered representative (see Table 2).

Once processed and packed, white rice is transported to the Mississippi State Port (670 km from Little Rock), where it is reloaded into a transoceanic freight ship and shipped to the Port of Rotterdam in the Netherlands (around $8000 \mathrm{~km}$ ). In Rotterdam the rice is loaded onto a lorry complying with EURO V to supply a supermarket in Geneva (930 km from Rotterdam). The EURO V emission standard was introduced in Europe in $2008^{14}$.

Since a passenger car, complying with EURO 5 and fuelled with diesel, is used to go to a supermarket $5 \mathrm{~km}$ away from home a larger volume of groceries is purchased each time. In Switzerland it is common to buy rice in $1 \mathrm{~kg}$ bags. Hence, one bag of rice of $1 \mathrm{~kg}$ is bought per shopping trip along with other groceries $(17 \mathrm{~kg})$. At home, the white rice is cooked on a gas stove fuelled with natural gas.

\subsection{Selected case study results}

The environmental impacts of cooked rice according to the three scenarios are quantified with the following four indicators relevant to the task forces:

- Global warming (global warming potentials, 100 year integration, IPCC 2013, Table 8.A.1)

- Fine particulate matter

- Land occupation (land competition, Guinée et al. 2001, Section 4.3.3

- Water withdrawal (gross water use, no scarcity weighting)

The indicators fine particulate matter, land occupation and water withdrawal represent a noncharacterised sum of PM2.5 emitted, $\mathrm{m}^{2}$ a of land occupied and $\mathrm{m}^{3}$ of water withdrawn, respectively.

Global warming: Global warming impacts are quantified in Figure 2 using the global warming potentials (100 years integration time) published in the main table of the 5th Assessment Report IPCC 2013. The TF also produced results, not shown here, for several modelling choices such as time horizon, with or without climate-carbon feedbacks, with and without NTCFs to test the sensitivity of LCA results to them. The production stage causes the largest share of greenhouse gas emissions in all three scenarios (see Figure 2). India demonstrates the highest overall impact on global warming due to the amount of greenhouse gases being emitted during cooking with firewood (76\% of it being nonsustainably harvested wood and thus giving rise for non-biogenic $\mathrm{CO}_{2}$ emissions). The higher greenhouse gas emissions of rice production in the US is due to a more elaborated inventory "rice, at farm /USA" compared to the inventory of Chinese rice production (see supplementary material) and should thus not be over-interpreted. The impact of distribution is lowest in India due to the small distance from the processing plant to the supermarket and the use of the bicycle for shopping.

Particulate Matter $(\mathbf{P M}<\mathbf{2 . 5} \mu \mathrm{m})$ : Figure 3 shows the sum of particulates $<2.5 \mu \mathrm{m}$ emitted during the four life cycle stages of the three scenarios. Most PM emissions arise during cooking with firewood on a three stone fireplace in India. Surprisingly, also cooking in the China scenario causes a substantial share of the PM emissions, which is due to their electricity being mostly generated from coal. The PM emissions of the "Distribution" stage are highest for the USA/Switzerland scenario because of the overseas transportation. However, this is a minor contribution to the overall PM emissions.

\footnotetext{
${ }^{11}$ Personal communication, April $30^{\text {th }}, 2015$

${ }^{12} \mathrm{http}: / /$ producersrice.com/rice-information Accessed on April 13 ${ }^{\text {th }}, 2015$

${ }^{13} \mathrm{https} / / / \mathrm{www}$.dieselnet.com/standards/us/hd.php Accessed on April $1^{\text {st }}, 2015$

${ }^{14}$ https://www.dieselnet.com/standards/eu/hd.php Accessed on April 1 $1^{\text {st }}, 2015$
} 
Land occupation: Agriculture and thus the "Rice production" stage occupies most land (see

). Rice cultivation in India occupies more land than rice cultivation in USA and China because of its lower yield. Furthermore, the considerably high land demand in the "Cooking" stage of India is due to the demand of firewood.

Water withdrawal: Nearly $100 \%$ of the water is withdrawn during the "Rice production" stage from ground- and surface water for irrigation as shown in

. All further life cycle stages contribute negligible shares to the total amount of withdrawn water.

\section{Conclusions}

The topical task forces are well on track in identifying and harmonising relevant and applicable environmental life cycle impact assessment indicators. While the global warming TF focuses on the most appropriate metrics among those published in the $5^{\text {th }}$ Assessment Report of IPCC IPCC 2013, the water use TF (WULCA) proposes a new scarcity based midpoint water use indicator. The particulate matter TF identified the best available model parameters to quantify human health effects caused by outdoor and indoor PM 2.5 emissions, listening to domain experts, and the land use TF identified species richness as a good starting point for a harmonised indicator and will explore complementary metrics such as vulnerability and habitat fragmentation. With local and regional variability the land use TF faces a similar problem like the water use TF did in the past and does still today. The crosscutting issues TF and the rice LCA case study help ensuring consistency across environmental indicators and applicability of the LCIA indicators proposed, respectively. The rice LCA case study with its multi-tier supply chains and generic processes will motivate the TF to provide generic as well as geographically and temporally differentiated harmonised indicators.

The results of the current work of the TF will be documented in white papers some of which will be published in scientific journals. The white papers will be the relevant input for the five days Pellston workshop $^{\mathrm{TM}}$, where delegates from the $\mathrm{TF}$ and further stakeholders will discuss and agree on best practice and harmonised life cycle impact assessment indicators as well as an update on the general LCIA framework. Based on the progress made in the last 12 months and the current state of discussions it is very likely that a relevant outcome will be produced during the Pellston workshop ${ }^{\mathrm{TM}}$ taking place in Valencia, Spain from 24 to 29 January 2016.

\section{Acknowledgement}

The authors acknowledge the contributions from the participants of the Basel, Barcelona and Adelaide workshops and of the different TFs, as well as the UNEP/SETAC Life Cycle Initiative for funding this activity.

\section{Disclaimer}

The designations employed and the presentation of the material in this publication do not imply the expression of any opinion whatsoever on the part of the UNEP/SETAC Life Cycle Initiative concerning the legal status of any country, territory, city or area or of its authorities, or concerning delimitation of its frontiers or boundaries. Moreover, the views expressed do not necessarily represent the decision or the stated policy of the UNEP/SETAC Life Cycle Initiative, nor does citing of trade names or commercial processes constitute endorsement.

\section{References}

Apte JS, Marshall JD, Cohen AJ, Brauer M (2015) Addressing global mortality from ambient PM2. 5. Environ Sci Technol 49 (13):80578066

Bayart J-B, Bulle C, Deschênes L, Margni M, Pfister S, Vince F, Koehler A (2010) A framework for assessing off-stream freshwater use in LCA. Int J Life Cycle Assess 15 (5):439-453

Blengini GA, Busto M (2009) The life cycle of rice: LCA of alternative agri-food chain management systems in Vercelli (Italy). J Environ Manag 90 (3):1512-1522

Blonk Agri-footprint BV (2014) Agri-Footprint - Part 2 - Description of data - Version 1.0. Gouda

Boulay A-M, Bare J, Benini L, Berger M, Klemmayer I, Lathuilliere M, Loubet P, Manzardo A, Margni M, Núñez M, Ridoutt B, Worbe S, Pfister S Building consensus on a generic water scarcity indicator for LCA-based water footprint: preliminary results from WULCA. In: LCA Food 2014, San Francisco, 2014.

Boulay A-M, Bare J, De Camillis C, Döll P, Gassert F, Gerten D, Humbert S, Inaba A, Itsubo N, Lemoine Y (2015) Consensus building on the development of a stress-based indicator for LCA-based impact assessment of water consumption: outcome of the expert workshops. Int J Life Cycle Assess 20 (5):577-583 
Brodt S, Kendall A, Mohammadi Y, Arslan A, Yuan J, Lee I-S, Linquist B (2014) Life cycle greenhouse gas emissions in California rice production. Field Crops Res 169:89-98

Burnett RT, Pope CA, Ezzati M, Olives C, Lim SS, Mehta S, Shin HH, Singh G, Hubbell B, Brauer M (2014) An integrated risk function for estimating the global burden of disease attributable to ambient fine particulate matter exposure. Environ Health Perspect 122 (4):397-403. doi:10.1289/ehp.1307049

Caiazzo F, Malina R, Staples MD, Wolfe PJ, Yim SH, Barrett SR (2014) Quantifying the climate impacts of albedo changes due to biofuel production: a comparison with biogeochemical effects. Environ Res Lett 9 (2):024015

Chapagain A, Hoekstra A (2011) The blue, green and grey water footprint of rice from production and consumption perspectives. Ecol Econ 70 (4):749-758

Chaudhary A, Verones F, de Baan L, Hellweg S (2015) Quantifying Land Use Impacts on Biodiversity: Combining Species-Area Models and Vulnerability Indicators. Environ Sci Technol 49 (16):9987-9995

Cherubini F, Bright RM, Strømman AH (2013) Global climate impacts of forest bioenergy: what, when and how to measure? Environ Res Lett 8 (1):014049

Coelho CR, Michelsen O (2014) Land use impacts on biodiversity from kiwifruit production in New Zealand assessed with global and national datasets. Int J Life Cycle Assess 19 (2):285-296

De Baan L, Mutel CL, Curran M, Hellweg S, Koellner T (2013) Land use in life cycle assessment: global characterization factors based on regional and global potential species extinction. Environ Sci Technol 47 (16):9281-9290

Fantke P, Jolliet O, Apte JS, Cohen AJ, Evans JS, Hänninen OO, Hurley F, Jantunen MJ, Jerrett M, Levy JI, Loh MM, Marshall JD, Miller BG, Preiss P, Spadaro JV, Tainio M, Tuomisto JT, Weschler CJ, McKone TE (2015) Health effects of fine particulate matter in life cycle impact assessment: Conclusions from the Basel guidance workshop. Int J Life Cycle Assess 20 (2):276-288

Fusi A, Bacenetti J, González-García S, Vercesi A, Bocchi S, Fiala M (2014) Environmental profile of paddy rice cultivation with different straw management. Sci Total Environ 494:119-128

Guinée JB, (final editor), Gorrée M, Heijungs R, Huppes G, Kleijn R, de Koning A, van Oers L, Wegener Sleeswijk A, Suh S, Udo de Haes HA, de Bruijn H, van Duin R, Huijbregts MAJ, Lindeijer E, Roorda AAH, Weidema BP (2001) Life cycle assessment; An operational guide to the ISO standards; Part 3: Scientific Background. Ministry of Housing, Spatial Planning and Environment (VROM) and Centre of Environmental Science (CML), Den Haag and Leiden, The Netherlands

Hodas N, Loh M, Shin H, Li DS, Bennett D, McKone TEM, Jolliet O, Weschler CJ, Jantunen M, Lioy P, Fantke P (2015) Indoor inhalation intake fractions of fine particulate matter: Review of influencing factors. Indoor Air. doi:10.1111/ina.12268

Hokazono S, Hayashi K (2012) Variability in environmental impacts during conversion from conventional to organic farming: a comparison among three rice production systems in Japan. J Clean Prod 28:101-112

IPCC (2013) The IPCC fifth Assessment Report - Climate Change 2013: the Physical Science Basis. Working Group I, IPCC Secretariat, Geneva, Switzerland

Jolliet O, Frischknecht R, Bare J, Boulay A-M, Bulle C, Fantke P, Gheewalaf S, Hauschild M, Itsubo N, Margni M, McKone T, Milà i Canals L, Postuma L, Prado-Lopez V, Ridoutt B, Sonnemann G, Rosenbaum RK, Seager T, Struijs J, van Zelm R, Vigon B, Weisbrod A (2014) Global guidance on environmental life cycle impact assessment indicators: Findings of the Glasgow scoping workshop. Int J LCA 19:962-967. doi:10.1007/s11367-014-0703-8

Jungbluth N (1997) Life-Cycle-Assessment for Stoves and Ovens. Umweltnatur- und Umweltsozialwissenschaften (UNS). Eidgenössische Technische Hochschule, Zürich

Motoshita M, Ono Y, Pfister S, Boulay A-M, Berger M, Nansai K, Tahara K, Itsubo N, Inaba A (2014) Consistent characterisation factors at midpoint and endpoint relevant to agricultural water scarcity arising from freshwater consumption. Int J Life Cycle Assess:1-12

Myhre G, Shindell D, Bréon F, Collins W, Fuglestvedt J, Huang J, Koch D, Lamarque J, Lee D, Mendoza B (2013) Anthropogenic and natural radiative forcing, Chapter 8 in Climate Change 2013: The Physical Science Basis. Contribution of Working Group I to the Fifth Assessment Report of the Intergovernmental Panel on Climate Change. IPCC Secretariat, Geneva, Switzerland

Nemecek T, Heil A, Huguenin O, Meier S, Erzinger S, Blaser S, Dux D, Zimmermann A (2007) Life Cycle Inventories of Agricultural Production Systems. Agroscope FAL Reckenholz and FAT Taenikon, Swiss Centre for Life Cycle Inventories, Dübendorf, CH

OECD/FAO (2014) OECD-FAO Agricultural Outlook 2014. doi:10.1787/agr_outlook-2014-en

Pfister S, Ridoutt BG (2013) Water footprint: pitfalls on common ground. Environ Sci Technol 48 (1):4-4

Ridoutt B, Fantke P, Pfister S, Bare J, Boulay A-M, Cherubini F, Frischknecht R, Hauschild M, Hellweg S, Henderson A, Jolliet O, Levasseur A, Margni M, McKone T, Michelsen O, Milà i Canals L, Page G, Pant R, Raugei M, Sala S, Saouter E, Verones F, Wiedmann T (2015a) Area of Concern: A new paradigm in life cycle assessment for the development of footprint metrics International Int J Life Cycle Assess (submitted)

Ridoutt B, Fantke P, Pfister S, Bare J, Boulay A-M, Cherubini F, Frischknecht R, Hauschild M, Hellweg S, Henderson A, Jolliet O, Levasseur A, Margni M, McKone T, Michelsen O, Milà i Canals L, Page G, Pant R, Raugei M, Sala S, Saouter E, Verones F, Wiedmann T (2015b) Making Sense of the Minefield of Footprint Indicators. Environ Sci Technol 49 (5):2601-2603

Ridoutt BG, Huang J (2012) Environmental relevance-the key to understanding water footprints. Proc Natl Acad Sci U S A 109 (22):E1424-E1424

Ridoutt BG, Sanguansri P, Nolan M, Marks N (2012) Meat consumption and water scarcity: beware of generalizations. J Clean Prod 28:127133

Shantappa D, Tirupataiah K, Yella R. K., Sandhyrani K, Mahendra KR, Malamasuri K (2014) Yield and Water Productivity of Rice under Different Cultivation Practices and Irrigation Regimes. Irrigated Water Resources Management (IWRM-2014)

Shine KP (2009) The global warming potential - the need for an interdisciplinary retrial. Clim Change 96 (4):467-472

Singh P, Gundimeda H, Stucki M (2014) Environmental footprint of cooking fuels: a life cycle assessment of ten fuel sources used in Indian households. Int J Life Cycle Assess 19 (5):1036-1048

Teixeira RF, de Souza DM, Curran MP, Antón A, Michelsen O, i Canals LM (2015) Towards consensus on land use impacts on biodiversity in LCA: UNEP/SETAC Life Cycle Initiative preliminary recommendations based on expert contributions. J Clean Prod 112:4283-4287

TERI (2013) TERI Energy Data Directory \& Yearbook 2012/13. TERI (The Energy and Resource Institute), New Delhi 


\section{Figure captions}

Figure 1: Product system and system boundary of the rice production, processing, distribution and cooking for the 3 scenarios. Country flags indicate the differences among the scenarios.

Figure 2: Global warming impact of $1 \mathrm{~kg}$ of cooked rice in the three scenarios, measured in $\mathrm{kg} \mathrm{CO}_{2}$ equivalents IPCC 2013, Table 8.A.1.

Figure 3: Particulate Matter $<2.5 \mu \mathrm{m}$ emitted per $\mathrm{kg}$ of cooked rice in the three scenarios, measured in $\mathrm{kg}$.

Figure 4: Land occupation per $\mathrm{kg}$ of cooked rice in the three scenarios, measured in $\mathrm{m}^{2} \mathrm{a}$ land occupied.

Figure 5: Water withdrawal per $\mathrm{kg}$ of cooked rice in the three scenarios, measured in $\mathrm{m} 3$ water withdrawn.

\section{Table captions}

Table 1: Economic allocation based on prices and volume fractions of the co-products of white rice Table 2: Key characteristics of the three scenarios

\section{Figures}

Figure 1:

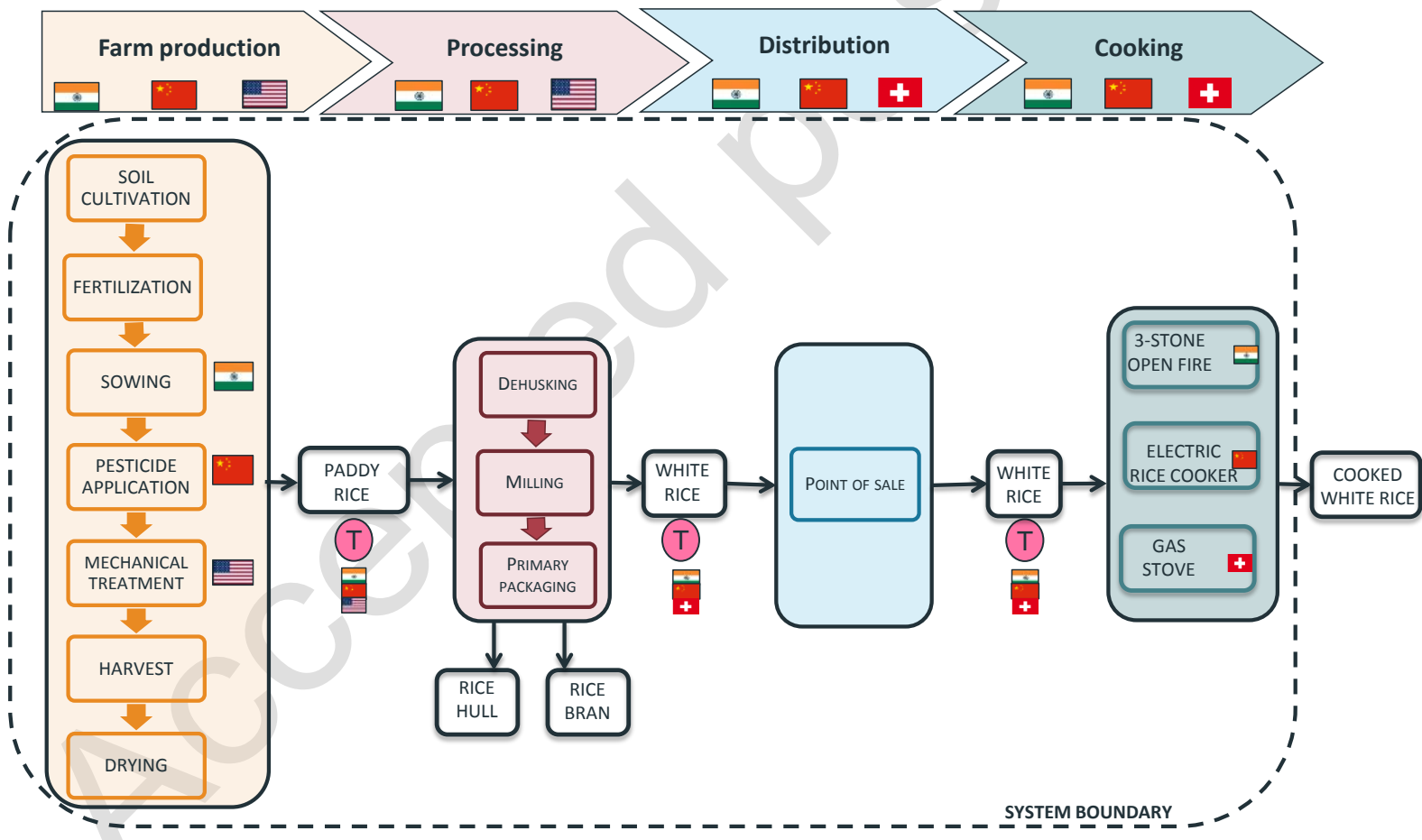


Figure 2:

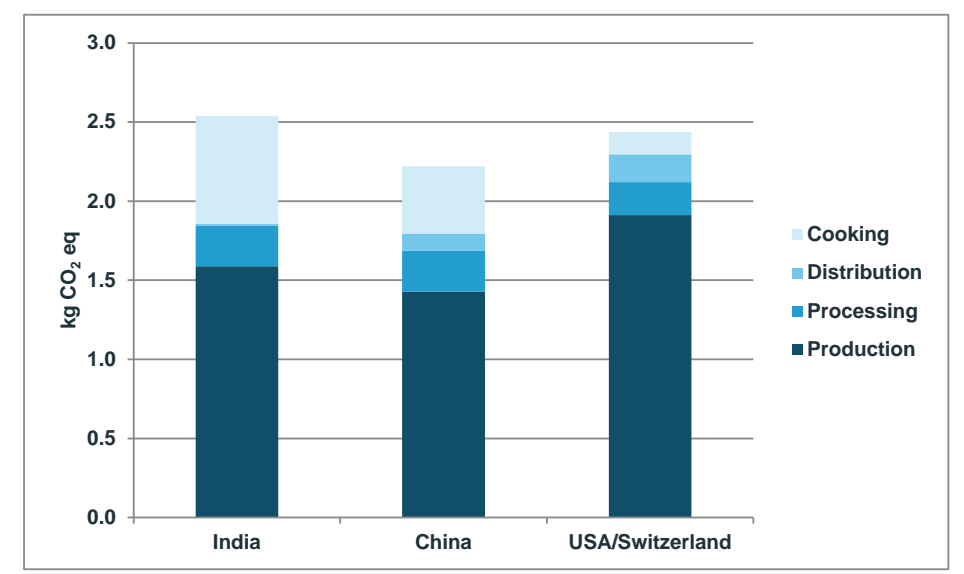

Figure 3:

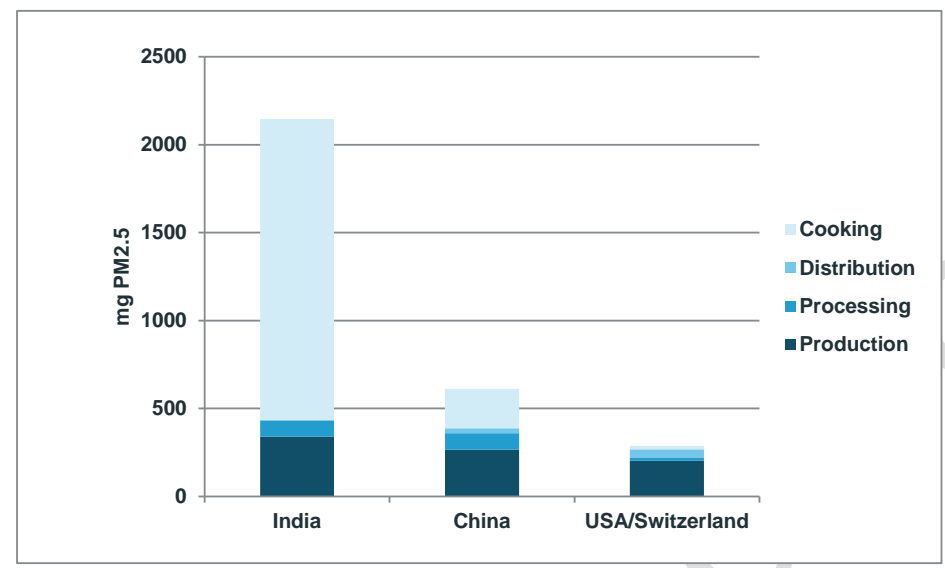

Figure 4:

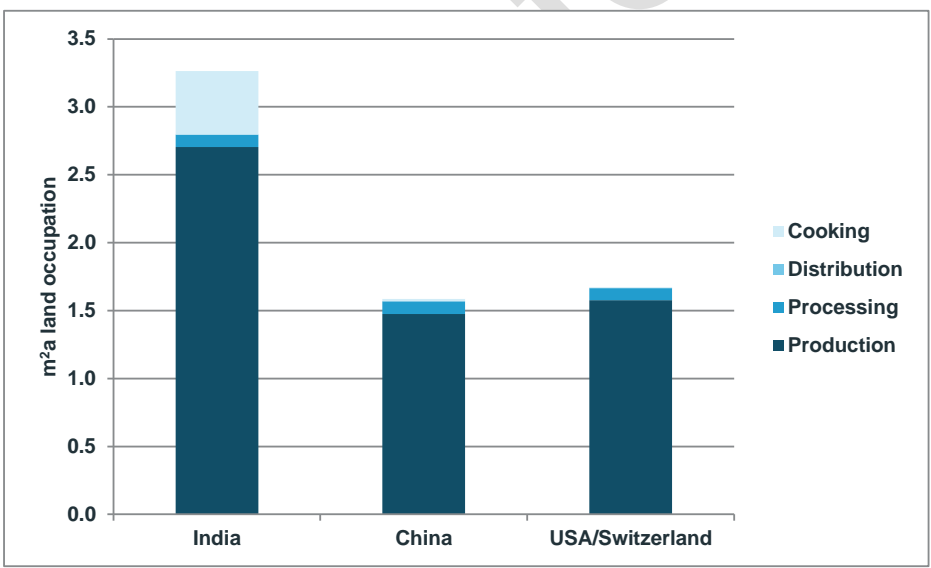


Figure 5:

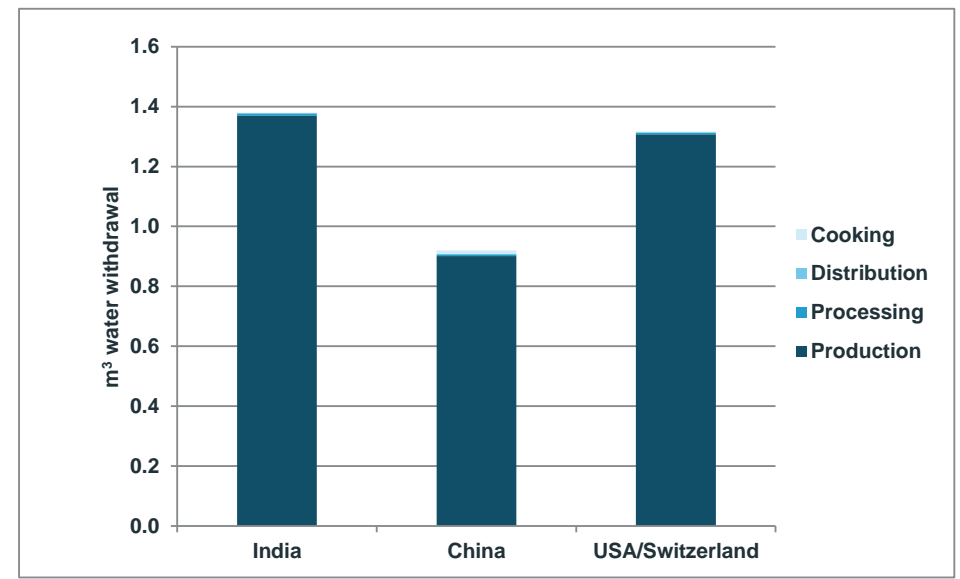

\section{Tables}

Table 1:

\begin{tabular}{|l|c|c|c|}
\hline & $\begin{array}{c}\text { Price } \\
{[\$ / \mathrm{kg}]}\end{array}$ & $\begin{array}{c}\text { Mass } \\
\text { allocation } \\
{[\%]}\end{array}$ & $\begin{array}{c}\text { Economic } \\
\text { allocation } \\
{[\%]}\end{array}$ \\
\hline White rice & $0.5^{2}$ & $70^{1}$ & 94 \\
\hline Rice husk & $0.01^{3}$ & $20^{1}$ & 1 \\
\hline Rice bran & $0.2^{3}$ & $10^{1}$ & 5 \\
\hline
\end{tabular}

http://www.knowledgebank.irri.org/step-by-step-production/postharvest/milling\#by-products Accessed on April 13th, 2015

2 http://oryza.com/oryza-white-rice-index-411-ton-april-01-2015 Accessed on April 1st, 2015 http://www.ams.usda.gov/mnreports/lswrice.pdf Accessed on April 6th, 2015 
Table 2:

\begin{tabular}{|c|c|c|c|c|}
\hline Life cycle stage & Unit & India & China & USA/Switzerland \\
\hline \multicolumn{5}{|l|}{ Cooking } \\
\hline Grocery shopping weight & $\mathrm{kg}$ & $10^{7}$ & $10^{7}$ & $18^{7}$ \\
\hline Mode of transport to point of sale & & bicycle & public bus & $\begin{array}{l}\text { car, diesel, EURO } \\
5\end{array}$ \\
\hline Distance from household to point of sale & $\mathrm{km}$ & 1.5 & 3 & 5 \\
\hline Water usage per kg cooked rice & 1 & $1.7^{8}$ & $1.1^{9}$ & $1.1^{9}$ \\
\hline Rice needed for $1 \mathrm{~kg}$ cooked rice & $\mathrm{kg}$ & \multicolumn{3}{|l|}{$0.7^{9}$} \\
\hline $\begin{array}{l}\text { Useful energy needed to cook } 0.7 \mathrm{~kg} \text { white } \\
\text { rice }\end{array}$ & kWh & \multicolumn{3}{|l|}{$0.3^{10}$} \\
\hline Cooking device & & $\begin{array}{l}\text { 3-stone- } \\
\text { open fire }\end{array}$ & $\begin{array}{l}\text { electric rice } \\
\text { cooker }\end{array}$ & gas stove \\
\hline Cooking fuel & & firewood & electricity & natural gas \\
\hline Energy efficiency of cooking device & $\%$ & $13.5^{11}$ & $90^{12}$ & $90^{12}$ \\
\hline
\end{tabular}

Blonk Agri-footprint BV (2014)

2 OECD/FAO (2014)

3 Nemecek et al. (2007)

4 Chapagain and Hoekstra (2011)

5 https://www.dieselnet.com/standards/ Accessed on April $1^{\text {st }}, 2015$

$6 \quad$ Blengini and Busto (2009)

7 Includes $1 \mathrm{~kg}$ of rice and $9 \mathrm{~kg}$ respectively $17 \mathrm{~kg}$ of other grocery items.

8 Personal communication, Peter Fantke, on April $30^{\text {th }}, 2015$

9 http://www.cooksinfo.com/rice

10 Personal measurement, Sybille Büsser Knöpfel, treeze Ltd, on April 9 $^{\text {th }}, 2015$

11 Singh et al. (2014)

12 Jungbluth (1997, p. 7) 